\title{
Serial measurements of midregion proANP and copeptin in ambulatory patients with heart failure: incremental prognostic value of novel biomarkers in heart failure
}

\author{
Wayne L Miller,' Karen A Hartman, ${ }^{1}$ Diane E Grill, ${ }^{2}$ Joachim Struck, ${ }^{3}$ \\ Andreas Bergmann, ${ }^{3}$ Allan S Jaffe ${ }^{1,4}$
}

${ }^{1}$ Division of Cardiovascular Diseases, Department of Medicine, Mayo Clinic, Rochester, Minnesota, USA ${ }^{2}$ Division of Biomedical Statistics and Informatics, Mayo Clinic, Rochester, Minnesota, USA

${ }^{3}$ BRAHMS Aktiengesellschaft (Part of ThermoFisher Scientific), Hennigsdorf, Germany

${ }^{4}$ Department of Laboratory, Medicine and Pathology, Mayo Clinic, Rochester, Minnesota, USA

\section{Correspondence to}

Dr Wayne L Miller, Division of Cardiovascular Diseases, Department of Medicine, Mayo Clinic, 200 First Street, SW,

Rochester, MN 55905, USA miller.wayne@mayo.edu

Accepted 27 October 2011 Published Online First 22 December 2011

\section{UNLCKI:}

This paper is freely available online under the BMJ Journals unlocked scheme, see http:// heart.bmi.com/site/about/ unlocked.xhtml

\begin{abstract}
Background Disease progression in heart failure (HF) reflects derangements in neurohormonal systems, and biomarkers of these systems can help to establish the diagnosis and assess the prognosis. Serial measurements of the precursor peptides of the natriuretic and vasopressin systems (midregional proatrial natriuretic peptide (MR-proANP) and C-terminal provasopressin (copeptin), respectively) should add incremental value to risk stratification in ambulatory patients with HF.
\end{abstract}

Methods and results $A$ cohort of 187 patients with class III-IV HF was prospectively enrolled, with biomarkers collected every 3 months over 2 years and analysed in relation to death/transplantation. Timedependent analyses (dichotomous and continuous variables) showed that increases in MR-proANP (HR 7.6, $95 \% \mathrm{Cl} 1.85$ to $31.15, \mathrm{p}<0.01$ ) and copeptin (HR 2.7, $95 \% \mathrm{Cl} 1.27$ to $5.61, \mathrm{p}=0.01$ ) were associated with increased risk, but, in multivariate analysis adjusted for troponin $\mathrm{T}$ (cTnT) $\geq 0.01 \mathrm{ng} / \mathrm{ml}$, only raised MR-proANP remained an independent predictor (HR $5.49,95 \% \mathrm{Cl}$ 1.31 to 23.01, $p=0.02$ ). Combined increases in MRproANP and copeptin (HR $9.01,95 \% \mathrm{Cl} 1.24$ to 65.26 , $\mathrm{p}=0.03$ ) with $\mathrm{cTnT}$ (HR 11.1, 95\% Cl 1.52 to 80.85 , $\mathrm{p}=0.02$ ), and increases $\geq 30 \%$ above already raised values identified the patients at greatest risk (MRproANP: HR 10.1, 95\% Cl 2.34 to 43.38, $\mathrm{p}=0.002$; copeptin: HR $11.5,95 \% \mathrm{Cl} 2.74$ to $48.08, p<0.001$ ).

Conclusions A strategy of serial monitoring of MRproANP and, of lesser impact, copeptin, combined with cTnT, may be advantageous in detecting and managing the highest-risk outpatients with HF.

\section{INTRODUCTION}

Despite advances in therapy, chronic heart failure (HF) is associated with an adverse prognosis ${ }^{12}$ and progresses in the absence of overt clinical events. ${ }^{34}$ Multiple neurohormonal pathways are activated, some of which are causally related and some are an effect of HF itself. ${ }^{5}$ One pathway, the natriuretic peptide system, is associated with adverse outcomes. ${ }^{6-8}$ Not only are they prognostic when initially measured but we have shown that the combination of B-type natriuretic peptide (BNP) and troponin $\mathrm{T}$ ( $\mathrm{c} \operatorname{TnT}$ ) measured every 3 months over 2 years provides incremental information about the progression of HF in outpatients. ${ }^{9}$ Most previous studies that evaluated changes over time monitored patients for short periods (typically 3-6 months) and/or used only single point-in-time measurements. ${ }^{8}{ }^{10-13}$ Given the importance of risk stratification, additional biomarkers that probe different neurohormonal pathways may further help to define disease progression and prognosis, which is likely to be dynamic and change over time. In addition, such biomarkers may provide novel pathophysiological insights and thus be synergistic with BNP/N-terminal (NT)-proBNP-guided therapy ${ }^{14}$ and standard clinical assessment (eg, New York Heart Association (NYHA) class) in making therapeutic decisions.

Midregional proatrial natriuretic peptide (MR-proANP) ${ }^{15}$ and C-terminal provasopressin (copeptin), a 39-amino-acid peptide derived from the prohormone preprovasopressin and cosecreted with arginine vasopressin from the posterior pituitary ${ }^{16}$ are precursor peptides related to different pathophysiological mechanisms in HF progression and have prognostic potential. ${ }^{10} 1117$ Recent data suggest that MR-proANP provides comparable diagnostic information to BNP in the acute setting. ${ }^{18} 19$

How much incremental information might be obtained from these new biomarkers, especially when assessed frequently over a prolonged period of time, remains to be evaluated. Accordingly, we measured MR-proANP and copeptin concentrations in outpatients with HF using the methods of design and analysis we reported previously for BNP and cTnT. ${ }^{9}$ Our hypotheses were that serial measurements at long-term follow-up would provide independent risk stratification similar, but additive, to that of BNP and $\mathrm{cTnT}^{20} 21$ and thus enhance identification of outpatients with HF who are at increased risk and would benefit from more intensive management. We pursued alternative analyses, assessing these analytes as continuous variables as well to make sure that we did not place them at a disadvantage by using the same analysis strategy as we previously used for BNP and cTnT.?

\section{METHODS \\ Patients and study design}

A cohort of 200 patients with NYHA class III and IV HF was prospectively enrolled from June 2001 to 
January 2004. Informed consent was obtained after a primary medical evaluation. Patients were excluded if cardiac revascularisation was anticipated within 6 months of enrolment, they were awaiting cardiac transplantation, or they had experienced an episode of acute HF decompensation within the past 30 days. Patients were followed at prespecified 3-month intervals ( \pm 3 weeks) for 24 months. The study was approved by the Mayo Foundation Institutional Review Board and included only patients who provided written consent as required by Minnesota Statute 144.335/ CFR 21 (Part 50).

\section{Study protocol}

Blood samples were collected in serum and EDTA, immediately placed on ice, processed and stored at $-70^{\circ} \mathrm{C}$ in divided aliquots until batch analysis was performed for each biomarker. Samples were collected and stored with the pre-hoc specification for multiple analyte evaluations. Precursor peptides (MR-proANP and copeptin) have been shown analytically to be very stable over time when stored at $-70^{\circ} \mathrm{C} .{ }^{10}{ }^{11}$ Clinicians and investigators were blinded to biomarker results. Left ventricular ejection fraction was derived by echocardiography performed up to 3 months before enrolment. An updated patient history and physical examination were completed at each follow-up visit by the primary HF specialist involved, as well as basic laboratory studies. Changes in drugs were recorded. Mean \pm SD follow-up duration was $18.9 \pm 7.8$ months.

\section{Biomarker measurements}

MR-proANP and copeptin concentrations were measured in EDTA plasma by immunoluminometric assays (CT-proAVP LIA (copeptin) and MR-proANP LIA) provided by BRAHMS Aktiengeselschaft (Henningsdorf, Germany) on a Berthold LB952 Auto CliniLumat Luminescence analyser. Copeptin (interassay and intra-assay $\mathrm{CVs}<10 \%$ ) and MR-proANP (interassay CV 2.3\%, intra-assay CV 3.6\%) were measured with coated-tube immunoluminometric assays. The details for BNP and cTnT measurements have previously been reported. ${ }^{9}$

Raised MR-proANP and BNP concentrations were defined as values $>95$ th centile of a normal population adjusted for age and gender. ${ }^{10} 22$ Raised copeptin concentrations were defined as $>7.1 \mathrm{pmol} / 1$ for women and $>9.4 \mathrm{pmol} / 1$ for men. ${ }^{11}$ Raised cTnT was defined as values $\geq 0.01 \mathrm{ng} / \mathrm{ml}^{23}{ }^{24}$ Renal function was determined by calculating estimated glomerular filtration rate $\left(\mathrm{ml} / \mathrm{min} / 1.73 \mathrm{~m}^{2}\right)$ using the modification of diet in renal disease equation. ${ }^{25}$

\section{Statistical analysis}

Continuous variables are reported as mean with SD and median with 25 th and 75 th centile IQRs. Categorical variables are reported as frequency of total values. Logarithmic transformation was performed to achieve approximate normal distribution for the biomarkers. The goal was to evaluate the relationships over time between the time until death or cardiac transplantation and serial MR-proANP and copeptin concentrations in relation to $\mathrm{CTnT}$ and BNP using the identical methodology and statistical analysis approach as used in our previous report $^{9}$ to ensure consistency in data handling. All modelling was performed with Cox proportional hazards models and executed using two different models. First, we included each biomarker as a continuous variable in univariate and multivariate models. Then, to facilitate the large numbers of cTnT observations that were below the limit of detection (ie, $<0.01 \mathrm{ng} / \mathrm{ml}$ ), we entered two variables, one a dichotomous variable indicating that the $\mathrm{cTnT}$ was below detectable levels (normal) and one variable using the logarithmic continuous measurements for cTnT values that were above $0.01 \mathrm{ng} / \mathrm{ml}$. Second, MR-proANP, copeptin and BNP (but not cTnT) data were analysed on the basis of tertiles for risk prediction and to facilitate clinical interpretation. Third, we categorised each of the biomarkers dichotomously as either 'raised' or 'not raised' based on the 95th centile of normal population data and the $0.01 \mathrm{ng} / \mathrm{ml}$ cut-off point for cTnT. Results from the Cox proportional hazards models are presented as HRs with corresponding 95\% CIs, $p$ values and C-statistics. ${ }^{26}$ Because of repeated data collection for all biomarkers and variety of enrolment times, enrolment (single value) and time-dependent (serial values) analysis methods were used. Kaplan-Meier survival curves summarise follow-up outcomes and account for changes in biomarker concentrations during the study period. Differences in survival curves were evaluated with log-rank tests. Likewise, in the time-dependent Cox multivariable models, patients were included in the initial proper risk set, but allowed to move between risk sets (higher risk and lower risk) over time. All other variables in these models are based on values at enrolment. Time-dependent Cox models were also used to evaluate changes in biomarkers between 3-month follow-up periods. To be included in this analysis, patients had to be followed to at least one 3-month visit after enrolment. Because changes in cTnT, but not BNP, were found to be statistically significant in these models, only cTnT was used to assess possible interactive effects. Analyses were carried out using SAS V.9 software ${ }^{27}$ or S-plus V.7. ${ }^{28}$

\section{RESULTS}

Table 1 shows the clinical and demographic characteristics of the cohort. Of the 200 patients enrolled, 13 had insufficient biomarker data, and therefore results are reported for 187 participants. Mean \pm SD duration of HF was $41.9 \pm 44.2$ months (median 31 months). Eight patients died before the initial 3month follow-up visit and provided only baseline data. Six (3\%) patients went on to cardiac transplantation, and $55(29 \%)$ patients died during the study.

At enrolment, MR-proANP and copeptin concentrations were raised in 157 (84\%) and 133 (71\%) of patients, respectively. Another 17 and 31 patients, respectively, developed new increases during the study. BNP was raised at enrolment in 122 patients $(65 \%)$, and cTnT concentrations were $\geq 0.01 \mathrm{ng} / \mathrm{ml}$ in 103 patients (55\%). During the study, another 31 patients each developed new increases in BNP and cTnT.

\section{Baseline single-sample biomarker analysis}

Univariate analysis was undertaken using all baseline variables including standard risk predictors of age, diabetes, hypertension, left ventricular ejection fraction and renal function. The following were shown to be the most significant predictors in this cohort: increasing NYHA class III-IV (HR 3.46, 95\% CI 1.75 to $6.83, \mathrm{p}<0.001)$, presence of biventricular pacing ( $\mathrm{HR}$ $2.79,95 \%$ CI 1.27 to $6.14, \mathrm{p}=0.011$ ), myocardial infarction history (HR 1.90, 95\% CI 1.13 to $3.19, \mathrm{p}=0.015$ ), stroke history (HR 2.29, 95\% CI 1.04 to 5.04, $\mathrm{p}=0.039$ ), raised BNP (HR 2.54, 95\% CI 1.35 to $4.78, \mathrm{p}=0.004$ ) and raised cTnT (HR 2.69, 95\% CI 1.54 to $4.72, p<0.001)$. Reduced risk was associated with a non-ischaemic aetiology of HF (HR $0.52,95 \%$ CI 0.28 to 0.98 , $\mathrm{p}=0.043$ ) and higher glomerular filtration rate (HR 0.98, 95\% CI 0.96 to $0.99, \mathrm{p}=0.005$ ). Covariate regression analyses for death/ transplantation based on single-sample measurements at study enrolment for MR-proANP and copeptin in an interaction model with $c \operatorname{Tn} T$ showed that only when increases were combined 
Table 1 Baseline demographics and clinical characteristics of patient cohort

\begin{tabular}{|c|c|c|c|}
\hline Variable & Mean \pm SD & $\begin{array}{l}\text { Median } \\
\text { (25-75\% IQR) }\end{array}$ & $\begin{array}{l}\text { No of } \\
\text { patients } \%\end{array}$ \\
\hline Age (years) & $71 \pm 10$ & $73(64-79)$ & 187 \\
\hline Male gender & & & $143(76.4)$ \\
\hline Caucasian/Native American & & & $185 / 2$ \\
\hline \multicolumn{4}{|l|}{ NYHA } \\
\hline Class III & & & $172(92.0)$ \\
\hline Class IV & & & $15(8.0)$ \\
\hline $\begin{array}{l}\text { Duration of heart } \\
\text { failure (months) }\end{array}$ & $41.9 \pm 44.2$ & $31(6-65)$ & 187 \\
\hline LVEF $(\%)$ & $27.3 \pm 12.2$ & $24(18-33)$ & 187 \\
\hline Weight (kg) & $87 \pm 23$ & $82(73-97)$ & 187 \\
\hline Height $(\mathrm{cm})$ & $172 \pm 9$ & $174(166-178)$ & 187 \\
\hline BMI $\left(\mathrm{kg} / \mathrm{m}^{2}\right)$ & $29.2 \pm 6.7$ & $28(25-32.5)$ & 187 \\
\hline Heart rate (beats/min) & $71 \pm 13$ & $71(62-80)$ & 187 \\
\hline Systolic BP (mm Hg) & $113 \pm 21$ & $110(98-124)$ & 187 \\
\hline Diastolic BP (mm Hg) & $63 \pm 11$ & $60(58-70)$ & 187 \\
\hline Haemoglobin (g/dl) & $12.5 \pm 1.7$ & $12.4(11.1-13.7)$ & 99 \\
\hline Serum creatinine, $\mathrm{mg} / \mathrm{dL}$ & $1.6 \pm 0.6$ & $1.5(1.3-1.9)$ & 187 \\
\hline $\mathrm{GFR}\left(\mathrm{ml} / \mathrm{min} / 1.73 \mathrm{~m}^{2}\right)$ & $46 \pm 15$ & $45(35-57)$ & 187 \\
\hline Potassium (mEq/l) & $4.4 \pm 0.9$ & $4.4(4.1-4.7)$ & 187 \\
\hline Sodium (mEq/l) & $139 \pm 4.1$ & $140(137-142)$ & 184 \\
\hline MR-proANP (pmol/l) & $395 \pm 304$ & $333(202-476)$ & 187 \\
\hline Copeptin (pmol/l) & $24.4 \pm 24.7$ & $16.6(7.3-31.1)$ & 187 \\
\hline BNP (pg/ml) & $408 \pm 423$ & $305(118-521)$ & 187 \\
\hline Troponin T (ng/ml) & $0.074 \pm 0.491$ & $0.013(0.005-0.035)$ & 187 \\
\hline \multicolumn{4}{|l|}{ Aetiology of HF } \\
\hline Ischaemic & & & $101(54.0)$ \\
\hline IDCM & & & $56(29.9)$ \\
\hline Hypertension & & & $5(2.6)$ \\
\hline Valvular & & & $7(3.7)$ \\
\hline Other & & & $18(9.6)$ \\
\hline Diabetes & & & $28(15)$ \\
\hline Hypertension & & & $120(64)$ \\
\hline Hyperlipidaemia & & & $121(65)$ \\
\hline COPD & & & $49(26)$ \\
\hline History of CABG & & & $82(44)$ \\
\hline BiV pacemaker & & & $27(14)$ \\
\hline AICD & & & $50(27)$ \\
\hline History of Ml & & & $91(49)$ \\
\hline History of CVA & & & $12(6)$ \\
\hline Never smoker & & & $68(36)$ \\
\hline Atrial fibrillation & & & $86(46)$ \\
\hline Aortic stenosis & & & $20(11)$ \\
\hline Aortic regurgitation & & & $46(24)$ \\
\hline Mitral regurgitation & & & $141(75)$ \\
\hline Tricuspid regurgitation & & & $130(70)$ \\
\hline History of valve replacement surgery & & & $17(9)$ \\
\hline \multicolumn{4}{|l|}{ Drugs } \\
\hline ACE1 & & & $140(75)$ \\
\hline ARB & & & $34(18)$ \\
\hline$\beta$-blocker & & & $147(78)$ \\
\hline Aldosterone blocker & & & $50(27)$ \\
\hline Digoxin & & & $113(60)$ \\
\hline Diuretic & & & $173(92)$ \\
\hline Aspirin & & & $114(61)$ \\
\hline Nitrates & & & $55(29)$ \\
\hline Antidysrhythmics & & & $40(21)$ \\
\hline
\end{tabular}

ACE1, angiotensin converting enzyme inhibitor; AICD, automatic implantable cardioverter defibrillator; ARB, angiotension receptor blocker; BiV, biventricular; BMI, body mass index; $B N P, B$-type natriuretic peptide; BP, blood pressure; COPD, chronic obstructive pulmonary disease; CVA, cerebrovascular accident; GFR, glomerular filtration rate; IDCM, idiopathic dilated cardiomyopathy; LVEF, left ventricular ejection fraction; MI, myocardial infarction; MR-proANP, midregional proatrial natriuretic peptide; NYHA, New York Heart Association. with $\mathrm{cTnT}$ did these biomarkers predict worse outcomes (MRproANP, HR 4.19, 95\% CI 2.50 to $11.67, \mathrm{p}=0.006$; copeptin, HR $3.69,95 \%$ CI 1.56 to $8.73, p=0.003$ ). When baseline peptide values were analysed as continuous variables (log transformed) in regression analysis, all biomarkers were univariate predictors of death/transplantation (table 2).

A model for covariate correction was developed before assessment of MR-proANP, copeptin, cTnT or BNP effects and included the significant univariate variables that were shown to be the most appropriate adjustment for this cohort given the number of events (NYHA class, history of myocardial infarction, and biventricular pacing) and without over-fitting the model. Multivariate analysis with adjustment for these univariate predictors (all data are not shown given that they revealed similar coefficients) showed baseline MR-proANP, copeptin and cTnT to be significant predictors of worse outcome (table 2).

\section{Time-dependent serial biomarker analysis}

Univariate time-dependent analyses (over 2 years) for prediction of death/transplantation showed that serial measurements of MR-proANP (HR 7.60, 95\% CI 1.85 to $31.15, \mathrm{p}=0.0048$ ) and copeptin (HR 2.67, 95\% CI 1.27 to $5.61, \mathrm{p}=0.0096$ ) were highly predictive. Figure 1A, B illustrates Kaplan-Meier survival analysis for these biomarkers including concentrations obtained at the last follow-up visit or the follow-up visit preceding an event. An increase in MR-proANP was the most potent predictor of poor outcome, and concentrations remaining normal were protective. In multivariate time-dependent modelling with serial MR-proANP and copeptin values adjusted for $c \operatorname{TnT} \geq 0.01 \mathrm{ng} /$ $\mathrm{ml}$, raised MR-proANP (HR 5.49, 95\% CI 1.31 to 23.01, $\mathrm{p}=0.02$ ), but not copeptin (HR 1.89, 95\% CI 0.89 to $4.13, p=0.6332$ ), persisted as an independent predictor. Multivariate analysis that included adjustment for the baseline univariate clinical predictors as described above revealed that the HR for cTnT was 2.31 $(p=0.003)$, and, with the separate additions of MR-proANP and copeptin to the model, the HR for MR-proANP was significant (4.56, $\mathrm{p}=0.039$ ), while copeptin did not contribute to risk prediction in the presence of raised cTnT (table 3 ).

When analysed in time-dependent models by tertiles, BNP, MR-proANP and copeptin revealed that the risk of death/transplantation was increased with increasing tertile, but risk prediction was not uniform. For BNP, tertile 2 (BNP $>115-337 \mathrm{pg} / \mathrm{ml}$ ) was not different from tertile $1(\leq 115 \mathrm{pg} / \mathrm{ml})$, while tertile 3 (>337 pg/ml) was significantly different from tertile 1 (HR 3.06 ,

Table 2 Univariate and multivariate continuous variable analysis of baseline single-sample biomarkers for risk of death/cardiac transplantation

\begin{tabular}{lllll}
\hline & $\begin{array}{l}\text { HR (75th } \\
\text { relative to } \\
\text { 25th centile) }\end{array}$ & $\begin{array}{l}\text { Observed } \\
\text { 25th and } \\
\text { 75th quartiles }\end{array}$ & p Value & C-statistic \\
\hline Univariate model & & & & \\
BNP (pg/ml) & 2.10 & $73-458$ & $<0.001$ & 0.648 \\
MR-proANP (pmol/l) & 2.57 & $191-487$ & $<0.001$ & 0.735 \\
Copeptin (pmol/l) & 2.83 & $8-32$ & $<0.001$ & 0.670 \\
Troponin T (ng/ml) & 2.14 & $<0.01-0.03$ & $<0.001$ & 0.666 \\
Multivariate model & & & & \\
BNP (pg/ml) & 1.88 & $73-458$ & 0.002 & 0.679 \\
MR-proANP (pmol/l) & 2.38 & $191-487$ & $<0.001$ & 0.758 \\
Copeptin (pmol/l) & 2.56 & $8-32$ & $<0.001$ & 0.740 \\
Troponin T (ng/ml) & 2.24 & $<0.01-0.03$ & $<0.001$ & 0.709 \\
\hline
\end{tabular}

Biomarkers were added separately to the multivariate model which included NYHA class, history of myocardial infarction, and presence of biventricular pacemaker. Models were fitted using natural log transformations of all continuous variables.

BNP, B-type natriuretic peptide; MR-proBNP, midregional proatrial natriuretic peptide. 

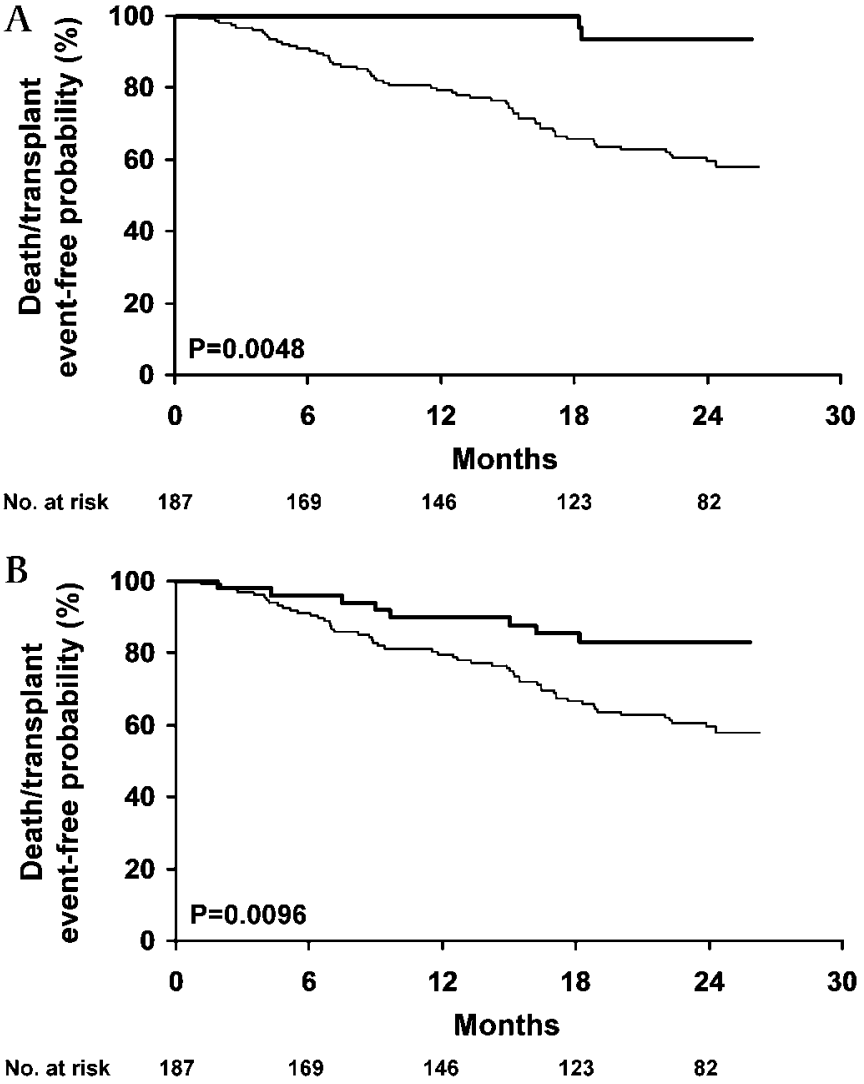

Figure 1 Kaplan-Meier curves for time-dependent event of death or cardiac transplantation for $(A)$ midregional proatrial natriuretic peptide (MR-proANP) and (B) C-terminal provasopressin (copeptin) grouped by category (increased (thin line; $>95$ th centile of normal, adjusted for age and gender, in $(A)$ and $>7.1 \mathrm{pmol} / \mathrm{l}$ for women and $>9.4 \mathrm{pmol} / \mathrm{l}$ for men in (B)) or not increased (thick line)) based on serial values over 2 years.

$\mathrm{p}=0.001)$. For MR-proANP, tertile 2 (>227-412 pmol/l) was significantly different from tertile 1 ( $\leq 227 \mathrm{pmol} / \mathrm{l})$ (HR 4.79, $\mathrm{p}=0.004)$, as was tertile 3 (>412 pmol/l) $($ HR 10.66, $\mathrm{p}<0.0001)$. Copeptin was similar to BNP in that tertile $2(>10.2$ to $25 \mathrm{pmol} / \mathrm{l})$ was not different from tertile 1 ( $\leq 10.2 \mathrm{pmol} / \mathrm{l})$, while tertile $3(>25 \mathrm{pmol} / \mathrm{l})$ was significantly different from tertile 1 (HR 4.08, p<0.0001).

\section{Analysis of changes in biomarkers over time}

Table 4 shows the predicted risk associated with changes in MRproANP from one follow-up visit to the next relative to MRproANP concentrations remaining normal. An increase at any time during follow-up carried a 4.35-fold increase in risk, which was not, however, statistically significant. This finding reflects

Table 3 Multivariate time-dependent analysis of risk for death/cardiac transplantation (Cox proportional hazard model)

\begin{tabular}{llrl}
\hline Variable & HR $(\mathbf{9 5 \%}$ CI) & p Value & C-statistic \\
\hline Raised BNP & $1.39(0.78$ to 2.48$)$ & 0.258 & \\
Troponin T $\geq 0.01 \mathrm{ng} / \mathrm{ml}$ & $2.18(1.25$ to 3.80$)$ & 0.006 & \\
NYHA class (IV vs III) & $3.28(1.63$ to 6.61$)$ & $<0.001$ & \\
History of myocardial infarction & $1.36(0.80$ to 2.32$)$ & 0.252 & \\
Biventricular pacemaker & $3.42(1.52$ to 7.68$)$ & 0.003 & \\
Raised MR-proANP* & $4.56(1.08$ to 19.32$)$ & 0.039 & 0.709 \\
Raised copeptin* & $1.86(0.84$ to 4.12$)$ & 0.126 & 0.705 \\
\hline
\end{tabular}

*Each biomarker added separately to the multivariate model. $\mathrm{B}=$ type natriuretic peptide BNP, NYHA, New York Heart Association; $\mathrm{Cl}$, confidence interval; HR, hazard ratio; MRproANP, midregional proatrial natriuretic peptide. that the majority of patients had raised concentrations of MRproANP at study enrolment and thus few patients were in this category of change (from normal to raised). However, modest $(<30 \%)$ increases or decreases (but not back to normal concentration) from an already raised MR-proANP value were associated with a significant change in risk (HR 5.79, $\mathrm{p}=0.016$ ). Furthermore, large increases $(\geq 30 \%$; a commonly cited level of significant change ${ }^{6}$ ) from already raised values of MR-proANP carried a very substantial increase in risk (HR 10.07, $p=0.002$ ). When the same analysis was carried out for copeptin (table 4), only large increases $(\geq 30 \%)$ from already raised values were associated with a further increase in risk (HR 11.48; $\mathrm{p}<0.001$ ). Raised values returning to normal during follow-up for either peptide were not associated with mitigation of risk, but this may reflect that few patients showed a lowering of values to below the 95th centile during the study; therefore there were too few patients in this category of change for meaningful statistical analysis.

\section{Time-dependent covariate biomarker analysis}

Risk prediction by covariate analysis for MR-proANP and cTnT when analysed for any time point during follow-up demonstrated that an increase in MR-proANP without any increase in cTnT predicted an increased risk of death/transplantation (HR 4.73, 95\% CI 1.0 to 20.43, $\mathrm{p}=0.037$ ). When cTnTwas raised ( $\geq 0.01 \mathrm{ng} /$ $\mathrm{ml}$ ) without an increase in MR-proANP, the risk analysis was confounded by too small a number of patients in this category. However, the combined increases in cTnT and MR-proANP augmented risk substantially (HR 10.29, 95\% CI 2.48 to 42.67 , $\mathrm{p}=0.0013$ ). A similar analysis for copeptin showed that only the combined increase with cTnT was associated with a significant increase in risk (HR 3.49, 95\% CI 1.63 to 7.49, $\mathrm{p}=0.0013$ ).

Covariate time-dependent models for serial measurements of MR-proANP and copeptin showed that neither biomarker, when increased in isolation, was a significant predictor. Combined increases in both biomarkers, however, were associated with increased risk (HR 9.01, 95\% CI 1.24 to 65.26, $\mathrm{p}=0.03$ ). Of particular interest is the observation in covariate analysis that the individual and combined increases in MR-proANP and copeptin when cTnTwas included in the analysis (but cTnTwas not raised) were no longer predictive, and the associated HR (5.93, 95\% CI 0.78 to $45.11, \mathrm{p}=0.086$ ) is lower than that noted when cTnT was not included in the analysis (HR 9.01). The combined increases in MR-proANP, copeptin and cTnT predicted a substantial increase in risk (HR 11.07, 95\% CI 1.52 to

Table 4 Effect of change in serial midregional proatrial natriuretic peptide (MR-proANP) and C-terminal provasopressin (copeptin) concentrations over the study period on outcome of death/cardiac transplantation

\begin{tabular}{|c|c|c|c|}
\hline Variable & HR $(95 \%$ Cl) & p Value & C-Statisti \\
\hline Normal to raised MR-proANP & 4.35 (0.61 to 31.02 ) & 0.143 & 0.641 \\
\hline $\begin{array}{l}\text { Raised MR-proANP to }<30 \% \\
\text { change (increase or decrease } \\
\text { but none back to normal value) }\end{array}$ & 5.79 (1.38 to 24.30$)$ & 0.016 & \\
\hline $\begin{array}{l}\text { Raised MR-proANP to } \geq 30 \% \\
\text { further increase in MR-proANP }\end{array}$ & 10.07 (2.34 to 43.38$)$ & 0.002 & \\
\hline Normal to raised copeptin & 4.11 (0.68 to 24.61$)$ & 0.122 & 0.684 \\
\hline $\begin{array}{l}\text { Raised copeptin to }<30 \% \\
\text { change (increase or decrease } \\
\text { but none back to normal value) }\end{array}$ & $4.20(0.95$ to 18.47$)$ & 0.058 & \\
\hline $\begin{array}{l}\text { Raised copeptin to } \geq 30 \% \text { further } \\
\text { increase in copeptin }\end{array}$ & 11.48 (2.74 to 48.08$)$ & $<0.001$ & \\
\hline
\end{tabular}

All values are relative to normal values remaining. $\mathrm{Cl}$, confidence interval; $\mathrm{HR}$, hazard ratio; MR-proANP, mid-regional proatrial natriuretic peptide. 
80.85, $\mathrm{p}=0.02)$. This was, however, not much greater than the combined increases in MR-proANP and cTnT when copeptin was excluded (HR 10.29, $\mathrm{p}=0.0013$ ).

\section{DISCUSSION}

Effective risk stratification is a key to success in the long-term management of HF, particularly for outpatients. The results of this study suggest that the conjoint use of MR-proANP with cTnT in outpatients with chronic HF can aid in this strategy. Indeed, in this dataset, MR-proANP provided more robust responses than BNP in most analyses. Copeptin was less robust. All the markers, as in other studies, demonstrated the prognostic value of single-sample increases including BNP and cTnT $^{6} 9$ 29-31; however, MR-proANP, and to a lesser extent copeptin, seemed to add support for an incremental value of serial measurements over time.

In categorical analysis, increases in MR-proANP and copeptin at baseline (single samples) or during clinical follow-up (serial samples) were univariately associated with an increased risk of death or cardiac transplantation. New increases from normal concentrations during follow-up did not statistically move patients into a higher risk category, but this is most likely due to the very high percentage $(\sim 70 \%)$ of patients entering the study with already raised concentrations of these biomarkers by study definition, and therefore relatively few patients were in this category of change to allow analysis. However, once raised, further increases significantly shifted patients to a higher risk category. These large increments (>30\%) in MR-proANP and copeptin defined the outpatients who were at highest risk. The large changes necessary to be clinically relevant once values are raised are similar to previous data for BNP and NT-proBNP where only large absolute or percentage changes were associated with clinically meaningful alterations in risk. ${ }^{32}$ For these biomarkers, changes up to $80 \%$ were required to show significant differences. Values returning to normal for either of the biomarkers did not mitigate risk, most likely because there were small numbers of patients in this category of change.

Of additional importance is the observation that increases in cTnT occurring at baseline or at any time during follow-up dramatically modulate the risk-prediction capacity of MRproANP or copeptin. While MR-proANP showed an independent contribution to risk stratification in multivariate timedependent analysis, a substantial incremental effect was also demonstrated when combined with cTnT. The interaction of combined increases in MR-proANP, copeptin and cTnT proved to be the most potent predictor of enhanced risk (HR 11.1, $p=0.02$ ), but not substantially different from the combined increases in MR-proANP and cTnT without copeptin (HR 10.3, $p=0.001)$. Increases in $c T n T$ seem to have a potentiating effect on the risk-predicting potential of increases in both MR-proANP and copeptin. Surprisingly, copeptin was less robust in timedependent analyses with cTnT than MR-proANP, but this may reflect differences in their pathophysiology. For copeptin to be a more potent predictor of risk, more advanced HF reflective of higher vasopressin release may be needed, as observed in decompensated patients. In continuous variable multivariate analysis using single-sample biomarker measurements, both biomarkers were predictive in the presence or absence of raised cTnT. This contrasts with the time-dependent categorical analysis (raised or not raised) where only MR-proANP remained a statistically significant independent predictor after adjustment for cTnT and clinical risk factors. This suggests that defining appropriate cut-off point values is central to the practical clinical use of these biomarkers in individual patients.
These findings suggest that the periodic monitoring of MRproANP, either separately or in combination with copeptin or particularly with cTnT, after an initial increase may be an effective means of defining meaningful changes in risk and better stratifying outpatients with HF. Our study population is similar to many others, and thus results in both this study and other analyses of other biomarkers should be helpful to physicians in following patients with systolic HF. In addition, insights from the impairment of these neurohormonal regulatory pathways may aid in developing new strategies to preclude new increases in these biomarkers or to intervene more effectively when they occur and thus aid patient prognosis. This may be especially promising for copeptin, serving as a surrogate for arginine vasopressin, to be a reliable biomarker of therapeutic response to vasopressin inhibition.

\section{Limitations of the study}

Of the study cohort, complete 2-year follow-up was not accomplished in 18 patients for reasons other than the primary end point. These patients elected not to continue participation in the study, but six had completed at least 1 year of follow-up and were censored at the time of their last visit. Eight patients died after enrolment but before the first 3-month follow-up visit and therefore contributed only enrolment data, but were considered part of the outcome analysis.

In conclusion, our data suggest that both clinically detectable and subclinical events occur in patients with HF based on discrete changes detected by serial biomarker surveillance, and these occur in apparently clinically stable outpatients. In our cohort, standard clinical assessment features such as change in NYHA class or renal function were not altered substantially over the course of the study to be a signal to the clinician of advancing risk. Increases in MR-proANP and copeptin $>95$ th centile of normal population detected by serial monitoring during follow-up in ambulatory patients appear to be common and predictive of increased risk of short-term events including death. The incremental predictive value of monitoring MRproANP over time alone, in combination with copeptin, and particularly with cTnT, may provide an effective and simple means of identifying ambulatory patients with $\mathrm{HF}$ who are at increased risk and allow timely intervention. Overall, our data also suggest that MR-proANP is equivalent, if not superior, to $\mathrm{BNP}$ in risk prediction alone and in combination with $\mathrm{cTnT}$. As such, MR-proBNP should also be considered a candidate biomarker in the developing area of natriuretic-peptide-guided therapy in patients with HF. ${ }^{14} 33$

Funding This work was supported in part by a grant from Siemens (Newark, Delaware, USA). Reagents were supplied by BRAHMS, now ThermoFisher Scientific (Richmond, Virginia, USA).

\section{Competing interests None.}

Patient consent Obtained.

Ethics approval Mayo Clinic Institutional Review Board.

Contributors All the authors contributed substantially to the execution of the study (WLM, KAH, ASJ), assay function (JS, AB, ASJ), development of the data and manuscript (WLM, ASJ) or the statistical analyses (DEG, WLM, ASJ). All have read and approved the manuscript.

Provenance and peer review Not commissioned; externally peer reviewed.

\section{REFERENCES}

1. McMurray J, Cohen-Solal A, Dietz R, et al. Practical recommendations for the use of ACE inhibitors, beta-blockers, aldosterone antagonists and angiotensin receptor blockers in heart failure: putting guidelines into practice. Eur $\mathrm{J}$ Heart Failure 2005; 7:710-21. 
2. Bristow MR, Saxon LA, Boehmer J, et al; for the Comparison of Medical Therapy, Pacing and Defibrillation in Heart Failure (COMPANION) Investigators. Cardiacresynchronization therapy with or without an implantable defibrillator in advanced chronic heart failure. New Engl J Med 2004;350:2140-50.

3. Konstam MA. Reliability of ventricular remodeling as a surrogate for use in conjunction with clinical outcomes in heart failure. Am J Cardiol 2005:96:867-71.

4. Davila DF, Nunez TJ, Oderman R, et al. Mechanisms of neurohormonal activation in chronic congestive heart failure: pathophysiology and therapeutic implications. Int J Cardiol 2005:101:343-6.

5. Wong M, Staszewsky L, Latini R, et al. Severity of left ventricular remodeling defines outcomes and response to therapy in heart failure: valsartan heart failure trial echocardiographic data. J Am Coll Cardiol 2004:43:2022-7.

6. Bettencourt P, Azevedo A, Pimenta J, et al. N-terminal-pro-brain natriuretic peptide predicts outcome after hospital discharge in heart failure patients. Circulation 2004;10:2168-74.

7. O'Brien RJ, Squire IB, Demme B, et al. Pre-discharge, but not admission levels of NT-proBNP predict adverse prognosis following acute left ventricular function. Eur $\mathrm{J}$ Heart Failure 2003;5:499-506.

8. Anand IS, Fisher LD, Chiang YT, et al; for the Val-HeFT Investigators. Changes in brain natriuretic peptide and norepinephrine over time and mortality and morbidity in the valsartan heart failure trial. Circulation 2003;107:1278-83.

9. Miller WL, Hartman KA, Burritt MF, et al. Serial biomarker measurements in ambulatory patients with chronic heart failure. Circulation 2007:116:249-57.

10. Masson S, Latini R, Carbonieri E, et al; on behalf of the GISSI-HF Investigators. The predictive value of stable precursor fragments of vasoactive peptides in patients with chronic heart failure: data form the GISSI-heart failure (GISSI-HF) trial. Eur J Heart Fail 2010;12:338-47.

11. Neubold S, Huelsmann M, Strunk G, et al. Comparison of copeptin, B-type natriuretic peptide, and amino-terminal pro-B-type natriuretic peptide in patients with chronic heart failure. J Am Coll Cardiol 2008;52:266-72.

12. Masson S, Latini R, Anand IS, et al; for the Val-HeFT Investigators. Prognostic value of changes in N-terminal pro-brain natriuretic peptide in Val-HeFT (Valsartan Heart Failure Trial). J Am Coll Cardiol 2008;52:997-1003.

13. Yan RT, White M, Yan AT, et al; for the Randomized Evaluation of Strategies for Left Ventricular Dysfunction (RESOLVD) Investigators. Usefulness of temporal changes in neurohormones as markers of ventricular remodeling and prognosis in patients with left ventricular systolic dysfunction and heart failure receiving either candesartan or enalapril or both. Am J Cardiol 2005;96:698-704.

14. O'Donoghue $\mathbf{M}$, Braunwald E. Natriuretic peptides in heart failure: should therapy be guided by BNP levels? Nat Rev Cardiol 2010;7:7-13.

15. Morgenthaler NG, Struck J, Thomas B, et al. Immunoluminometric assay for the midregion of pro-atrial natriuretic peptide in human plasma. Clin Chem 2004;50:234-6

16. Morgenthaler NG, Struck J, Alonso C, et al. Assay for the measurement ofcopeptin, a stable peptide derived from the precursor of vasopressin. Clin Chem 2006;52:112-19

17. Von Haehling S, Jankowska EA, Morgenthaler NG, et al. Comparison of midregional pro-atrial natriuretic peptide with $\mathrm{N}$-terminal pr-B-type natriuretic peptidein predicting survival in patients with chronic heart failure. J Am Coll Cardio 2007; 50:1973-80.

18. Maisel A, Mueller C, Nowak R, et al. Mid-region pro-hormone markers fordiagnosis and prognosis in acute dyspnea. J Am Coll Cardiol 2010;55:2062-76.

19. Dieplinger $\mathbf{B}$, Gegenhuber $A$, Haltmayer $M$, et al. Evaluation of novel biomarkers for the diagnosis of acute destabilised heart failure in patients withshortness of breath Heart 2009;95:1508-13.

20. Perna ER, Macin SM, Cimbaro Canella JP, et al. Ongoing myocardial injury in stable severe heart failure. Value of cardiac troponin T monitoring for high-risk patient identification. Circulation 2004;110:2376-82

21. Ishii J, Nomura M, Nakamura $Y$, et al. Risk stratification using a combination of cardiac troponin $T$ and brain natriuretic peptide in patients hospitalized for worsening chronic heart failure. Am J Cardiol 2002;89:691-5

22. Redfield MM, Rodeheffer RJ, Jacobsen SJ, et al. Plasma brain natriuretic peptideconcentration: Impact of age and gender. J Am Coll Cardiol 2002:40:976-82

23. The Joint European Society of Cardiology/American College of CardiologyCommittee. Myocardial Infarction Redefined-A Consensus Document of The JointEuropean Society of Cardiology/American College of Cardiology Committee for theRedefinition of Myocardial Infarction. J Am Coll Cardiol 2000;36:959-69.

24. Apple FS, Wu AHB, Jaffe AS. Guidelines for redefinition of myocardial infarction. How to use existing assays clinically and for clinical trials. Am Heart $J$ 2002;144:981-6

25. Levey AS, Coresh J, Balk E, et al. National kidney foundation practice guidelinesfor chronic kidney disease: Evaluation, classification, and stratification. Ann Intern Med 2003;139:137-47.

26. Kremer WK. Concordance for Survival Time Data: Fixed and TimeDependentcovariates and Possible Ties in Predictor and Time. Rochester, MN: Technical report series \#80, Mayo Clinic, 2007.

27. SAS Institute Inc. SAS®/STAT User's Guide, Version 9 edition. Cary, NC: SAS Institute Inc, 2005.

28. Insightful Corporation (1988-2005). S-PLUS Version 7.0 for Unix (Computer Software). Seattle, Washington: Insightful Corporation, 2005.

29. Healey JS, Davies RF, Smith SJ, et al. Prognostic use of cardiac troponin T and troponin I in patients with heart failure. Can J Cardiology 2003;19:383-6.

30. Hudson MP, O'Connor CM, Gattis WA, et al. Implications of elevated cardiac troponin $\mathrm{T}$ in ambulatory patients with heart failure: a prospective analysis. Am Hear J 2004:147:546-52.

31. Erna ER, Macin SM, Cimbaro Canella JP, et al. High levels of troponin T are associated with ventricular remodeling and adverse in-hospital outcome in heart failure. Med Sci Monit 2004:10:CR90-5.

32. Miller WL, Hartman KA, Grill DE, et al. Only large reductions in concentrations of natriuretic peptides (BNP and NT-proBNP) are associated with improved outcome in ambulatory patients with chronic heart failure. Clin Chem 2009:55:78-84.

33. Januzzi JL, Rehman SU, Mohammend AA, et al. Use of amino-terminal pro-B-type natriuretic peptide to guide outpatient therapy of patients with chronic left ventricula systolic dysfunction. J Am Coll Cardiol 2011;58:1881-9. 